\title{
High School Teachers' Perceptions of the Intercultural Communicative Language Teaching (ICLT) ModelApplied in Language Classrooms- A Case Study of a Vietnamese High School
}

\author{
Nguyen Thi Ngoc Hanh ${ }^{1}$, Nguyen Hai Quan ${ }^{2}$ \\ ${ }^{1}$ Bachelor, School of Foreign Languages, Can Tho University, Vietnam \\ ${ }^{2}$ Doctor, School of Foreign Languages, Can Tho University, Vietnam
}

\begin{abstract}
This study exemplifies itself as an attempt to bridge theory and practice in developing high school learners' intercultural communicative competence (ICC) through language teaching. In particular, it aims to introduce the Intercultural Communicative Language Teaching (ICLT) model to teachers through seminars for teaching practice in a high school context. Teachers' perceptions of the model were investigated via two rounds of interviews and classroom observations. Ten teachers in a high school in the Mekong Delta Region participated in the first stage of seminars and round-one interviews and three continued to proceed to the second phase of lesson planning and teaching practice. Findings from the study revealed a high level of awareness the teachers had regarding the need to integrate cultural aspects and develop students' ICC. The teachers perceived contextual conditions in their school as favourable for integrating cultural contents in their English lessons. Yet, the urge to abide by the prescribed curriculum and textbooks, and the exam backwash effects appeared to discourage them to confidently adopt a more language-culture balanced approach in teaching. The teachers were also found to wholeheartedly welcome the ICLT model for its values in promoting more weight on cultural aspects and bringing more motivation to learners. The model was perceived as teacher-friendly and highly feasible in their context thanks to its resemblance to the CLT teaching approach that they were familiar with. Heavy workload in lesson preparation, time restriction in the curriculum and teachers' lack of confidence in their own cultural and intercultural knowledge and skills were found to be key challenges to the teachers' practice when the ICLT model was applied.
\end{abstract}

Key words: ICC, Vietnamese high school context, ICLT model, teachers' perceptions

\section{INTRODUCTION}

Culture has been well justified as an inseparable part of foreign language education (Byram, 1989, 1997; Kramsch, 1993, 1998; Brooks, 2001; Cullen, 2000). Developing students' knowledge of cultures and their intercultural communicative competence (ICC), as such, has become a crucial goal of language teaching, especially in the $21^{\text {st }}$ century. Meanwhile, English, as an international language, is now used as a means of communication between speakers of multicultural contexts and backgrounds. Globally, there has been a gradual expansion in the use of this particular language from the Inner Circle (Kachru, 1985) or between speakers whose mother tongue is English (e.g., the United Kingdom, the United States, Australia, New Zealand) and those who use English as a second language or from the Outer Circle (e.g., in the Philippines, Singapore, India) to the Expanding Circle where speakers from countries such as Thailand, China, Indonesia, Vietnam and Germany increasingly employ English as a foreign language for communication (Crystal 2003; Kirkpatrick 2007; Mckay\&Bokhorst-Heng, 2008). In conjunction with this expanding popularity of the language is an updated definition of a competent speaker,which is no longermerely as one with a good command of language competence. Rather, for successful and effective communication, along with language proficiency, a competent speaker needs to demonstrate a good repertoire of cultural sensitivity, knowledgeand skills since these 
DOI: $\underline{10.51386 / 25815946 / \mathrm{ijsms}-\mathrm{v} 4 \mathrm{i} 5 \mathrm{p} 103}$

enablethem to communicate effectively with interlocutors who come from diverse cultures (Tran\& Duong, 2018).

This updated definition of communicative effectiveness has posed a new challenge for English teachers worldwide concerning how to integrate language and culture in teaching so as to effectively develop learners' ICC as expected. In reality, research evidence has suggested that "teachers in different classrooms in different parts of the world still ignore the importance of teaching culture as a part of language study" (Gonen and Saglam, 2012). This study also pointed out numerous reasons behind teachers' ignorance or downplaying of cultural contents in their language classrooms. First, contextual factors such as time restriction in the compulsory curriculum and pressure to prepare students for structure-based examinations (Gonen\&Saglam, 2012; Hong, 2008) have been identified as key hindering conditions. Moreover, it has been highlighted that the key reason for this reality might reside right in the teachers' lack of confidence with their own expertise of intercultural communication(Sercu, 2005) together with insufficient knowledge of effective methods for incorporating cultural contents into their language lessons. In light of these previous research findings, an alarm bell has been rung concerning the pressing need for teachers in different contexts to be sufficiently provided with professional development activities that target not only their language proficiency but also their intercultural knowledgetogether with practical skills to effectively facilitate the development of their students' cultural and intercultural competence.

Such an urgent need could be apparently censored in the context of Vietnam where learners' communicative competence has been identified as a central pillar in language teaching and learning (Canh, 2011; MOET, 2006). Over the past decade, massive projects have been launched by the central government to drive the whole language teaching sector towards this important goal. Accordingly, a plethora of innovations have been undertaken, including curriculum revision and textbook development. At thehigh school level, one important innovative feature of the new textbook series "TiengAnh 10, 11 and 12" is the strong highlight of the cultural and intercultural aspects incorporated in the section "Culture and Communication" in each unit. The textbooks, as such, are promoted as a good reflection of "cross cultural values (Vietnamese, regional and AngloAmerican) across a wide range of contexts in Vietnam, in South-East Asia and in some main English-speaking countries" (Hoang, 2015, p.7). Together with these significant efforts, the ultimate goal - the development of students' ICC might continue to be limited unlessclassroom practitioners are well-equipped with a good level of confidence in their knowledge of culture as well as their pedagogical expertise for successful culture-language integration in teaching. Up to date, however, almost training provided to teachers across the country seems to put a central focus on improving their language proficiency and teaching methodology. As such, endeavours to empower teachers with more practical aspects for effective culture-languageteaching might provide a fruitful avenue for a joint effort in improving the quality of language teaching in general.

In light of this situation, the curent study aims to promote a new model for integrating language and culture in teaching English to high school students and investigate the teachers' perceptions of its values in their own teaching context. In particular, the study aims to introduce the Intercultural Communicative Language Teaching (ICLT) model proposed by Tran (2016) and Tran and Duong (2018) for Vietnamese context. The study was centred on the following three specific questions.

(1) As reported by the teachers, how are cultural aspects and ICC currently taught in their context?

(2) What perceptions do the teachers hold towards the ICLT model when it is first introduced?

(3) What benefits and challenges do the teachers perceive when applying the model in their own teaching context?

\section{LITERATURE REVIEW}

\section{A. Conceptualisations and theoretical foundations of ICC}

The origin and development of the concept intercultural competence could be traced back in a number of linguistic theories. The term competence that was proposed by Chomsky (1965) in his influential generativetransformational theory refers to "knowledge of an ideal speaker-hearer" and is separated from performance, 
DOI: $\underline{10.51386 / 25815946 / \mathrm{ijsms}-\mathrm{v} 4 \mathrm{i} 5 \mathrm{p} 103}$

defined as the ability to use language. This seminal term, however, paved the way for the development of sociolinguisticknowledge in Hymes's (1972) conceptualisation of communicative competence. Accordingly, socio-linguistic knowledge is viewed as knowledge of culture, society and communicative context that speakers tap into to tailor their language for appropriate use in communication. The importance of sociolinguistic knowledge in communication continues to be reaffirmed in subsequent categorisations of communicative competence. For example, in Canale and Swain's (1980) model, the role of sociocultural rules of use is emphasized as a crucial part of communicative competence in Bachman and Palmer's (1996) framework, the importance of sociocultural knowledge is housed under the name pragmatic competence, which integrates speakers' sociolinguistic knowledge with speech acts - key components that enable speakers to produce utterances in accordance with their communicative goals.

Defining intercultural competence has been considered as a complex task (Moeller \& Nugent, 2014). However, intercultural competence could be defined as individuals' ability to interact appropriately and effectively with people from other cultural backgrounds (Sinecrope et al., 2012). In this sense, a good understanding of culture and the ability to employ linguistic knowledge and skills to function appropriately in communication could be seen as an integral part of intercultural competence. Furstenberg (2010), however, warns that since culture is "a highly complex, elusive, multilayered notion that encompasses many different and overlapping areas and that inherently defies easy categorization and classification" (p. 329), the task of identifying which cultural aspects to integrate in the language classroom is seen as highly challenging. Given this complexity, however, specific characteristics or features of intercultural competent speakers appear to be easily identified. Sercu (2005), for instance, suggests that key characteristics of intercultural competence include speakers' willingness to engage with the foreign culture, their self-awareness and ability to look upon themselves from the outside, to see the world through others' eyes, to cope with uncertainty, to act as a cultural mediator and to evaluate others' points of view. Therefore, ICC is considered as a multifaceted concept that encompasses not only knowledge but also awareness, self-awareness, attitudes and specific skills to act and function well in multicultural communicative contexts.

Attempts to categorize specific components of ICC have been featured in various conceptualising frameworks in the literature. Among those existing models, the ones suggested by Sercu et al. (2005) and Byram (1997) are often referred to as most comprehensive. Accordingly, Sercu et al. (2005)'s outline three main components of ICC which include knowledge, skills/ behaviour and attitudes/traits. As can be seen in Table 1, each of these categories embodies a number of subcomponents and explanations. These specifications on each aspect of knowledge, skills and attitudes provide clear guidelines to classroom practitioners concerning what cultural and intercultural contents, skills or abilities and attitudes they could incorporate in language lessons as well as what evidence to look for in assessing students' ICC.

Table 1:Sercu et al's (2005)components of Intercultural Competence

\begin{tabular}{|c|c|c|}
\hline Knowledge & Skills/behaviour & Attitudes/traits \\
\hline $\begin{array}{l}\text { - Culture specific and culture } \\
\text { general knowledge } \\
\text {-Knowledge of self and other } \\
\text { - Knowledge of interaction: } \\
\text { individual and societal } \\
\text { - Insight regarding the ways in } \\
\text { which culture affects } \\
\text { language and communication } \\
\text { Savoirs }\end{array}$ & $\begin{array}{l}\text { - Ability to interpret and relate } \\
\text { Savoir-comprendre } \\
\text { - Ability to discover and/or } \\
\text { interact } \\
\text { - Ability to acquire new } \\
\text { knowledge and to operate } \\
\text { knowledge, attitudes and } \\
\text { skills under the constraints of } \\
\text { real-time communication and } \\
\text { interaction } \\
\text { - Meta cognitive strategies to } \\
\text { direct own } \\
\text { Savoir-apprendre } \\
\text { savoirs-faire }\end{array}$ & 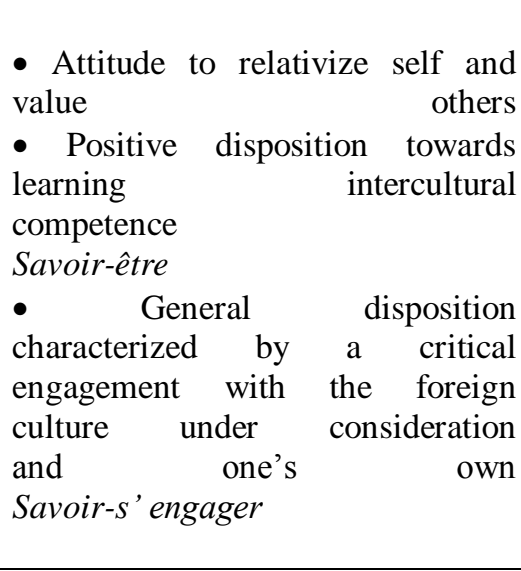 \\
\hline
\end{tabular}


DOI: $\underline{10.51386 / 25815946 / \mathrm{ijsms}-\mathrm{v} 4 \mathrm{i} 5 \mathrm{p} 103}$

The components outlined in Sercu et al. (2005)'s model, to a great extent, are aligned with what Byram (1997) proposes in his framework of ICC. Yet, as illustrated in Table 2, Byram's model appears to provide more fine-grained categorisations of ICC and directly connect these with the field of language teaching and learning.Explanations for each of the components together with detailed objectives for integrating these components in language teaching are also provided. Tapping into similar aspects of ICC including knowledge, skills and attitudes, Byram, however, sub-divides skills into two groups of "interpret and relate" and "discourse and/ or interact" and consider "political education and critical cultural awareness" as a central part of ICC. In this model, the components of ICC are further related to linguistic competence, sociolinguistic competence and discourse competence, and these together formulate specific educational objectives in language and culture learning and serve as guiding criteria to develop and assess learners' ICC in the foreign language classroom

Table 2:Byram's (1997) model of Intercultural Communicative Competence

Byram Model of Intercultural Communicative Competence

\begin{tabular}{|c|c|c|}
\hline & $\begin{array}{c}\text { Skills } \\
\text { interpret and relate } \\
\text { (savoir comprendre) }\end{array}$ & \\
\hline $\begin{array}{c}\text { Knowledge } \\
\text { of self and other; } \\
\text { of interaction, individual } \\
\text { and societal } \\
\text { (savoirs) }\end{array}$ & $\begin{array}{c}\text { political education and critical } \\
\text { cultural awareness } \\
\text { (savoir s'engager) }\end{array}$ & $\begin{array}{c}\text { Attitudes } \\
\text { relativizing self and } \\
\text { valuing other } \\
\text { (savoir être) }\end{array}$ \\
\hline & $\begin{array}{c}\text { Skills } \\
\text { discover and/or interact } \\
\text { (savoir apprendre/faire) }\end{array}$ & \\
\hline
\end{tabular}

Note. From Teaching and Assessing Intercultural Communicative Competence, by M. Byram, 1997, p. 34. Copyright 1997 by Multilingual Matters.

Drawing on these theoretical standpoints, ICC, in the context of the current study, is defined as the speakers' ability to perform or function appropriately and effectively in multicultural contexts or with people coming from various cultural backgroundsbasing on their understanding, knowledge and awareness of their own and other cultures s. This competence consists of the four key components asknowledge, skills, attitudes and awareness that teachers need to pay due attention to in teaching English to their students.

\section{B. The Intercultural Communicative Language Teaching Model}

As earlier mentioned, one important objective of the current research was to put the Intercultural Communicative Language Teaching (ICLT) model into practical use in a high school context. As informed by findings from previous studies, teachers in different contexts had a tendency to neglect cultural contents and ICC in language teaching due to insufficient confidence in their own cultural and intercultural knowledge as well as a lack of a principled model for developing effective culture-language integrated lessons. The attempt undertaken in this current study, as such, could be seen as an exemplification of efforts to respond to this practical problem by bridging the gap between theory and practice in the field of language teaching.

The Intercultural Communicative Language Teaching (ICLT) model (Tran, 2016; Tran \& Duong, 2018), which was suggested for the particular context of Vietnam, was chosen for a number of reasons. For one thing, it was developed on the basis of important theories and hypotheses in language teaching and learning including Krashen's (1985) Hypothesis of Comprehensible Input, Long's (1985, 1996) Hypothesis of Interaction, Swain's $(1995,2000)$ Hypothesis of Output, and Schmidt's $(1995,2001)$ Noticing Hypothesis. For another, the model provides teachers with a detailed and well-explained procedure for lesson planning and implementation. Specific stages and steps for designing and sequencing lessons that allow teachers to effectively combine 
DOI: $\underline{10.51386 / 25815946 / \mathrm{ijsms}-\mathrm{v} 4 \mathrm{i} 5 \mathrm{p} 103}$

language and culture as well as the underlying rationale for each step are also provided. In this way, the model not only supplies teachers with a template to employ in teaching practice but further empowers them with clear justifications for their lesson design.

As depicted in Figure 1, the ICLT model is an on-going process of ICC acquisition with a strong emphasis on the integration of language and culture and intercultural communicative competence as an official core objective of the teaching process. Within this model, the arrows among the components indicate the sequence of the process, and the dotted arrows depict the interrelationship between the main part and the foundation and the ultimate goal of the ICLT process. There are three parts in this model: Language-Culture, the main training process (Input - Notice - Practice - Output), and ICC, which are systematically integrated. As can be seen, language and culture are closely intertwined and presented as two crucial teaching content components that need to be addressed in a balanced manner in language lessons so as to effectively uphold learners' development of language and intercultural communicative competence.

Figure 1: The Intercultural Communicative Language Teaching (ICLT) model (Tran, 2016; Tran \& Duong, 2018)

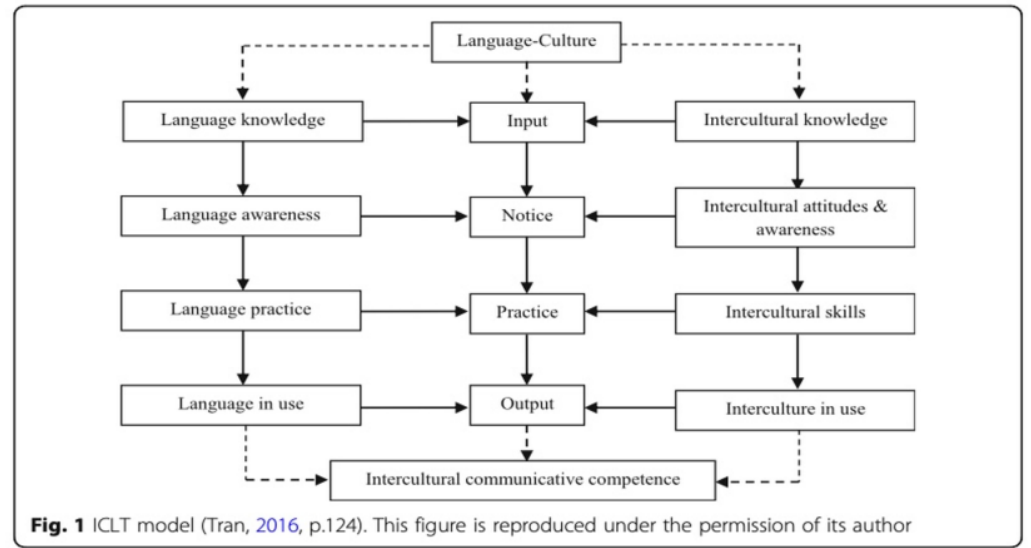

Central to the model is the teaching procedure with four steps: Input-Notice-Practice-Output. The first step, Input, based onKrashen's (1985) Comprehensible Input Hypothesis, is viewed as a critical phase where necessary input is scaffolded and learners engage in comprehensible language and intercultural knowledge as foundations for subsequent development of awareness and skills. Following this, the step of Notice, which is formed on the basis of Schmidt's Noticing Hypothesis (Schmidt, 1995, 2001), aims at raising learners' language awareness and intercultural awareness and adjusting their intercultural attitudes by exposing them to more authentic learning tasks or activities so that they can practise, notice and make comparisons between unknown features of the input with familiar ones. In the third step, Practice, learners have a variety of opportunities to participate in guided communicative tasks that facilitate their internalization of the language input and refine their intercultural awareness and attitudes. Underpinned by Long's $(1985,1996)$ Interaction Hypothesis, this stage is considered important to the development of learners' intercultural skills in conjunction with their language ability. In this step, learners also have opportunities to practise using intercultural language strategies for communication in accordance to their language and cultural needs. In the final step, Output, which is based on Swain's $(1995,2000)$ Output Hypothesis, learners are able to further explore the new language and intercultural features by trying out new forms, expressions, or strategies derived from the earlier input through language and intercultural tasks (e.g., project, drama, presentation, etc.). It is in this stage that learners' awareness of gaps in their language and intercultural competence is raised, which triggers new input for another process of the ICLT model (Tran, 2016; Tran \& Duong, 2018). 
DOI: $\underline{10.51386 / 25815946 / \mathrm{ijsms}-\mathrm{v} 4 \mathrm{i} 5 \mathrm{p} 103}$

As presented, the ICLT model, which was designed specifically for Vietnamese context, showcases a strong link between linguistic and cultural knowledge, awareness and skills in an integral manner. The model not only provides teachers with a clear guideline with specific steps for their lessons but also lays a clear underlying theoretical foundation enhancing teachers' understanding of why the model is designed in such a manner. The model is expected to, if effectively put into practice, help learners develop their knowledge of other cultures, adjust their attitudes to other cultures, improve their awareness of cultural differences, develop skills to function appropriately and effectively in communicating with people from other cultures in tandem with the development of the ability to exploit language for successful communication (Tran \&Seepho, 2016). Such a fine-grained model is also expected to enable classroom practitioners to develop lesson plans and implement their lessons in a doable manner.

\section{Related Study}

Quite an extensive body of research was found to be devoted to the investigation of various aspects in relation to ICC in the literature. Among these, one important strand of research has drawn its focus towards the relationship between students' ICC and their communicative competence. For instance, Genc and Bada (2005), Doganay and Yergaliyeva (2013), who explored the learners' perceptions towards ICC integrated into English courses, reported that their learners perceived that intercultural competence could improve their English communicative competence, especially speaking skills. Popsecu and Iordachescu (2015) also reported in their ICC-related experimental study that learners' linguistic knowledge improved remarkably. Similarly, several other studies (e.g. Liaw, 2006; Planken et al., 2004; Popsecu\&Iordachescu, 2015) consistently found that ICC had positive effects on learners' ability to communicate in a foreign language. As also contended by Planken et al. (2004), learners taking the foreign language program into which ICC was integrated were found to have a richer vocabulary bank and better oral and written skills in the foreign language learned. In this sense, findings from this research body suggest that efforts in developing ICC among students might lead to improvements in both their language competence for communication and their ICC.

Studies have also explored teachers' perceptions of the importance of ICC and their strategies in teaching ICC in EFL classrooms. Particularly, in the study by Boontharika (2018), the results showed that university teachers perceived ICC as the understanding of other cultures and having knowledge of other cultures. They believed that ICC was the cultural knowledge of each country, which could not be ignored while learning the language. Teacher participants in this study agreed that ICC was essential and should be promoted in language classes although each of them was found to employ different strategies to promote ICC in their classes including explaining cultural diff erences explicitly, reading and discussion task, role play, presentation task and real-world task, compare and contrast strategy, reading stories etc.

The third group of studies placed its focus on investigating the factors that affect teachers' efforts to integrate cultural contents and ICC into their language classrooms and lessons. Accordingly, a number of important factors have been identified. Among these, one common factor reported was the teachers' lack of a firm grasp of ICC and how to integrate it into their teaching, as pointed out by an extensive number of studies (e.g. Atay, Kurt, Çamlibel, Ersin\&Kaslioglu, 2009; Gu, 2016; Sercu, 2006; Tran \& Dang, 2014; Cheng, 2007). These studies pointed out that although teachers had positive views toward ICC, they rarely integrated the cultural and intercultural dimensions into their classrooms because they did not thoroughly understand the intercultural approach to language teaching and ICC. Without a firm grasp, most teachers teach culture in the traditional way simply by passing cultural knowledge or information onto learners which is not likely to help learners become intercultural speakers or acquire ICC (Barletta Manjarrés, 2009; Gu, 2016; Sercu, 2006). Another key factor reported to hinder teachers from fully adopting the intercultural approach to language teaching and integrating ICC into their teaching was that there lacks a consistent method or model for dealing with culture in a language classroom (Garrido\&Álvarez, 2006; Manjarrés, 2009). Garrido and Álvarez (2006) claimed that this lack of consistency in culture teaching methodology made it hard for teachers to set cultural objectives for teaching and learning in a language classroom.

Apart from the above factors, inadequate administrative support and learning materials that can be used to promote ICC in a language classroom can also be considered as major obstacles to ICC integration into 
DOI: $\underline{10.51386 / 25815946 / \mathrm{ijsms}-\mathrm{v} 4 \mathrm{i} 5 \mathrm{p} 103}$

language teaching (Manjarrés, 2009; Garrido\&Álvarez, 2006; Gu, 2016; Young \&Sachdev, 2011). As also reported, ICC was still not viewed as a major goal for foreign language learning in the eyes of teachers, learners and their parents (Sercu, 2006) and that teachers did not have enough time to cover the cultural contents due to the heavy curriculum contents they needed to cover (Karbinar\&Guler, 2013). As highlighted by the results of these previous studies, teachers in practice were still dealing with a plethora of factors that demotivated and hindered their attempts to promote cultural contents and ICC in language teaching. As such, unless close attention is drawn towards these factors, endeavours to encourage teachers to implement a more culturally integrated approach might not be fruitful as expected.

Along with these factors, another group of research investigated specific difficulties that teachers encounter when implementing an intercultural approach in their EFL classroom practice. Findings from these studies have highlighted three main categories of difficulties. In particular, as Hanna (2016) described, the first major problem lied in the fact that teachers had trouble finding and evaluating material regarding the concept of IC. Second, it is also challenging since teachers seem to lack knowledge and understanding of IC, which might disable teachers from evaluating materials. Hanna (2016) explained that as teachers did not hold a thorough understanding of the concept or had not been exposed to the concept in their teacher education, they might find themselves unprepared to teach it. Lastly, teachers' unwillingness to change has been discussed. In Asian context, such hesitation might result from the fact that teachers tend not to see ICC as an important contributing component of their students' language competence. In some cases, teachers downplay the role of ICC since it is not officially included in the syllabus as important teaching contents. In some other studies, it was found that teachers showed concerns over letting students discuss different cultures because potential racist opinions might come up to the surface, which teachers then would have to deal with.

A few attempts have been made to put pedagogical models for integrating language and culture together in language classrooms. For instance, in the action research on the effects of the ICLT model on EFL learners' ICC in the context of foreign language centers by Tran and Duong (2018), the study showed that the ICLT model was seen an effective form of intercultural language education to facilitate the achievement of learners' ICC (both LC and IC). Generally, both the learners' LC and IC developed in a similar pattern, which indicates that learners can acquire intercultural content through language content and vice versa. This study might suggest that in a long term the ICLT model can equip learners with ICC in order to become intercultural speakers who can be fluent in a foreign language and function appropriately and effectively in the context of globalization. According Tran and Duong (2018), the ICLT model should be experimented at various educational levels in different contexts in order to further confirm the effectiveness of this model. Such a proposal has also been signaled by Hanna (2016), stating that a lack of research that crosses specifically the upper secondary school teachers and culture-language integrated teaching is noticeable. As she explained, studies conducted in Asia mainly focus on university teachers' beliefs and, a large number of studies do not specify on what level the participating teachers actually teach.

This review of the existing literature has highlighted the importance of cultural contents and ICC as a crucial contributing component of the speakers' communicative competence. It also brought into light specific challenges that teachers in different contexts confronted in their attempts to draw more attention towards these ICC components in language teaching. Meanwhile, it further signals a lack of practical attempts to put theoretical models into practice due to some obstacles that teachers often face in their teaching environment, an important gap that the current study aims to respond to.

\section{METHODOLOGY}

\section{A. Research Design}

The present study employed a qualitative design with data collected via semi-structured interviews with individual teachers, classroom observations and group interviews. In terms of procedure, the study included two phases. In the first phase, the researcher organised two seminars to introduce the ICLT model to the teachers together with necessary guidelines for lesson planning and implementing. A model lesson was also developed and delivered by the researcher. Immediately after the seminars, the first round of interviews with each teacher participant was conducted with a focus on exploring the teachers' current practice in integrating cultural aspects 
DOI: $\underline{10.51386 / 25815946 / \mathrm{ijsms}-\mathrm{v} 4 \mathrm{i} 5 \mathrm{p} 103}$

and ICC in their teaching and their initial perceptions of the ICLT model. Following this, in the second phase, three teachers who agreed to try applying the model into practice worked together to develop lesson plans and delivered these lessons to their own classes with observations done by three of them. After each lesson, a group interview was conducted concentrating on the teachers' reflection upon specific benefits and challenges they experienced when using the model for teaching.

Table 3: Research Procedure

\begin{tabular}{|c|c|c|c|}
\hline Stage & Time & Activities & Objectives \\
\hline \multirow[t]{8}{*}{ Stage 1} & Week 1 & Preparing contents for seminars & \multirow{8}{*}{$\begin{array}{l}\text { This stage aims to introduce the ICLT } \\
\text { model to high school teachers, } \\
\text { investigate the reality of teaching } \\
\text { cultural aspects and ICC in their } \\
\text { context and their perceptions towards } \\
\text { the model at the beginning of the } \\
\text { course. } \\
\text { (Research questions 1,2) }\end{array}$} \\
\hline & & Preparing interview questions & \\
\hline & & Piloting interviews & \\
\hline & \multirow[t]{3}{*}{ Week 2} & Seminars & \\
\hline & & $\begin{array}{l}\text { Demonstrating teaching the ICLT } \\
\text { model ( } 1 \text { lesson })\end{array}$ & \\
\hline & & Inviting other two teachers & \\
\hline & \multirow[t]{2}{*}{ Week 3- } & Interviewing teachers & \\
\hline & & Data analysis & \\
\hline \multirow[t]{5}{*}{ Stage 2} & Week 4 -12 & Preparing lesson plans & \multirow{5}{*}{$\begin{array}{l}\text { This stage aims at determining } \\
\text { benefits and challenges teachers } \\
\text { perceive when they apply the model } \\
\text { in their teaching context; and their } \\
\text { perceptions towards it at the end of } \\
\text { the course. }\end{array}$} \\
\hline & & Teaching practice & \\
\hline & & & \\
\hline & Week 13 & Interviewing teachers & \\
\hline & Week 15 & Data Analysis & \\
\hline
\end{tabular}

\section{B. Participants}

In terms of participants, 10 teachers in a high school in the Mekong Delta Region where the researcher has been working in the past 12 years got involved in the study. As can be seen in Table 1, the teachers' ages range from 30 to 50 years old. They included 6 female teachers and 4 male ones. For confidential and ethical reasons, pseudo-names were used for these teachers as A, B, C, D, E, F, G, H and I, J respectively. Among these, 3 (A, B and the researcher) participated in the second phase of teaching practice using the ICLT model. In terms of qualifications, four teachers have Master degrees (B, E, and F, J) and six teachers with Bachelor degrees in English teacher education (A, C, D, G, H and I). With regard to the researched context, the high school where these teachers were working is a gifted school and considered as one of the best schools in the province. The majority of the participants had extensive teaching experience, ranging from 9 to 27 years of teaching. 
DOI: $\underline{10.51386 / 25815946 / \mathrm{ijsms}-\mathrm{v} 4 \mathrm{i} 5 \mathrm{p} 103}$

Table 4: Participants' background information

\begin{tabular}{|c|c|c|c|c|}
\hline $\begin{array}{l}\text { Teachers' } \\
\text { Names }\end{array}$ & Age & Gender & $\begin{array}{l}\text { Years of } \\
\text { experience }\end{array}$ & Qualifications \\
\hline A & 32 & $\mathrm{~F}$ & 10 & Bachelor \\
\hline $\mathrm{B}$ & 40 & $\mathrm{~F}$ & 10 & Master \\
\hline $\mathrm{C}$ & 33 & M & 9 & Bachelor \\
\hline $\mathrm{D}$ & 37 & $\mathrm{~F}$ & 15 & Bachelor \\
\hline E & 39 & $\mathrm{~F}$ & 17 & Master \\
\hline $\mathrm{F}$ & 39 & $\mathrm{~F}$ & 17 & Master \\
\hline $\mathrm{G}$ & 48 & $\mathrm{M}$ & 25 & Bachelor \\
\hline $\mathrm{H}$ & 50 & $\mathrm{M}$ & 27 & Bachelor \\
\hline I & 48 & $\mathrm{~F}$ & 25 & Bachelor \\
\hline $\mathrm{J}$ & 33 & M & 10 & Master \\
\hline
\end{tabular}

\section{FINDINGS}

\section{A. Teachers' current practices in teaching cultural aspects and ICC}

The first focus in the present study was to examine the teachers' current practices concerning the extent they integrated cultural and inter-cultural aspects in their language classrooms. In the first interviews with all 10 teachers, the researcher followed a semi-structured interview protocol to elicit the teachers to provide descriptions in relation to this issue. One of the first prominent findings revealed by the interview data was the teachers' consistent perception on the favourable contextual conditions that supported their efforts to integrate culture in language teaching. In particular, as described by the teachers, they all had much experience in teaching English at a high school for more than 9 years with good proficiency (all got C1 level of CEFR). They all agreed that the school where they were working was well-equipped with sufficient facilities for teaching. Also, as Teacher G reported, every year, the school also got some native teachers to teach English to students for several months. $100 \%$ participants also said that the students in this school had better knowledge and behaviors than those in other schools because they were well selected from the exam of selection with high competitiveness. In addition, they supposed that there was a good cooperation between students and teachers in their teaching and learning. The teachers also perceived that they had strong support from the school managers for innovations in teaching and learning. These convenient conditions are clearly illustrated in Teacher A's comment below.

I have been teaching English for over 10 years. I am often in charge of grade 10 and 11. My teaching environment brings good conditions for teachers in their teaching. The teaching atmosphere is friendly. My high school is one of the schools for the gifted, so my students are good ones and cooperate well with teachers in learning. Students in my schools are better than those in other schools because they have to pass the exam of selecting students with high marks (Teacher A, block 2).

The teachers were also found to have a good awareness of the importance of including cultural contents and ICC as important objectives in their language teaching. In the interviews, all teachers contended that it was necessary for high-school teachers to include cultural knowledge in their English lessons for different reasons. For example, Teacher A thought that the inclusion of the period of "Communication and Culture" in the new English textbooks proved that culture is an important part in teaching English nowadays because "it helps 
DOI: $\underline{10.51386 / 25815946 / i j s m s-v 4 i 5 p 103}$

students improve cultural knowledge, recognize the differences and similarities between their own cultures with other cultures" (block 12). Similarly, Teacher B stated that integrating culture contents into teaching languages can help "learners communicate properly and avoid making embarrassing mistakes" (Block 43). Teacher B further explained that cultural contents were important to be included since "if students had a good understanding of others' cultures, they can integrate well in diverse cultures, widen their knowledge of the world and become good global citizens" (Block 43).Evident in these comments was a strong belief in the necessity to treat cultural contents as an integral part of language lessons in high school level.

Given the teachers' uniform perceptions towards the favourable conditions and the importance to include cultural contents and ICC in language teaching, there seems, however, to be a lack of focus on these aspects in their present classrooms. As revealed by the interviews, 8 of the 10 teachers reported that they did not pay enough attention to teaching culture/ cultural knowledge or developing students' intercultural knowledge and competence. The other two teachers (Teacher $\mathrm{C}$ and $\mathrm{E}$ ) said that they did focus on teaching cultural contents, but due to the limit time reserved for these contents in the curriculum, they confessed that they basically covered the "Communication and Culture" Section in the book and considered it as the only way they covered cultural content (Teacher C \& E, Blocks 69 \& 131). In alignment with this insufficient attention to these cultural components, the teachers also appeared to hold quite vague ideas about the objectives they set for students in relation to cultural contents. In particular, when asked what objectives they focused on when including cultural contents in their lessons, cultural knowledge was the only target the teachers described along with language knowledge and skills. None of the teachers, however, touched into the other important aspects of awareness, skills and attitudes as suggested in Byram's (2005) model. To a certain extent, this revealed modest level of awareness and understanding of cultural and ICC aspects that they teachers should be aware of in teaching practices.

To tell the truth, before participating the seminars, the objectives in teaching cultural aspects are similar to teaching other language skills. But now, I hoped my students can be aware of their own culture, understand and accept the differences among diverse cultures to help them communicate more suitably. Besides understanding their own cultures and other countries', I hope that will affect the awareness and attitudes of students so that they will behave properly and become good citizens (Teacher B, block 49)

With regards to the teaching method, evidence from the teachers' interviews indicated a lack of a principled and consistent approach for promoting cultural contents in their current language teaching. Although the teachers claimed to be using CLT as the main teaching method, to a large extent, their cultural lessons appeared to reflect a high level of alignment with the prescribed content in the textbook, with particular reference to the section "Culture and Communication". Following this, most teachers described that they typically provided vocabulary and structures input in the pre-stage before moving to the "Communication" Section in the practice-stage and ending with the post-stage of "Culture". In most cases, these lessons included reading and speaking skills, taught separately without a clear connection. To some extent, this reality points out two important issues. First, the teachers' practice was strongly constrained by the content and the design of the textbooks they employed in teaching. Second, even though the teachers perceived these sessions as main parts in the lessons that helped them address cultural contents in the program, they could hardly go beyond the focus on language and a rather shallow introduction of cultural knowledge to their students through reading or speaking activities.

I often designed the period "Communication and Culture" as other skills: listening, speaking, writing, reading. I used CLT approach with warm-up activities to lead to the lesson. Then I will go through each part "Communication", first pre-activities before listening or speaking about Vietnamese culture in Communication. Then I come to "Culture" after I teach my students some vocabulary in Cultural lesson. Students will do tasks in "Culture" part (Teacher A, block 16).

\section{B. Teachers' initial perceptions about the ICLT model}

As explained earlier, the teachers' initial perceptions of the ICLT model was explored through the semistructured interviews conducted right after the model was introduced to them via two seminars. Accordingly, evidence from the interview data showed that the three prominent themes emerged included (1) the teachers' consistent perceptions of the familiarity of the model with their current method in teaching, (2) its high level of 
DOI: $\underline{10.51386 / 25815946 / \mathrm{ijsms}-\mathrm{v} 4 \mathrm{i} 5 \mathrm{p} 103}$

feasibility in their context, and (3) its values in upgrading their understanding of the objectives in language and culture integrated teaching.

First of all, although the participants acknowledged that it was their first time to be introduced to the ICLT model, they all perceived a great extent of familiarity with the model. In specific, all teachers felt that there was so much similarity between what this model promotes with the communicative language teaching method (CLT) that they claimed to have used in their teaching context. They further highlighted the clear resemblance in terms of the three lesson stages of Pre, While and Post in both models. However, the teachers also highlighted one important distinctive feature in the ICLT model, which was the step of "Notice" which they perceived as crucial for students to recognize the similarities and differences of cultural aspects of different countries. As explained by Teacher A,

I think that model has similar steps as CLT method: pre-, while-, post-, but I can see that there are some activities in Notice such as comparisons and discussions about the similarities and differences between Vietnam and other cultures. Students can use cultural knowledge that they have just learnt to create essays or talks after they compare the two differences (Teacher A, block 26).

I think the model is effective and can be used to teach cultural aspects to improve students' ICC. This model really combines many methods, including input, practice and output. However, there is Notice part, which can help students remember cultural knowledge. It motivates teachers to use videos, pictures and search for a lot of information (Teacher A, block 28).

Another important finding evident from the teachers' interviews was their strong belief in its feasibility for application in high school contexts. After participating in the seminars, all participating teachers thought that it was feasible to apply the model in their classrooms. As they explained, with this model, students could have more opportunities to realize their own culture and compare it with the others' cultures. Teacher G, for example, said that "the ICLT model helps students improve language skills and cultural knowledge as well" (block 207). Teacher B also explained that students could withdraw their own lesson and create their own languages after learning the period of the ICLT model. They also felt that the model provided them with a suitable platform for connecting the 2 parts of Communication and Culture together in their lessons, as indicated in Teacher B's opinion below:

I think that model has many good things to learn. For example, we can know steps to teach: Input, notice, practice and output. I believe that although there are 2 parts in "Communication and Culture", but we try to design our lessons according to these steps so that our students could remember, understand, be aware of the differences of cultures, and compare them. Students could create their own products such as essays, talks. It is based on CLT approach, but the culture contents are much more focused (Teacher B, block 55).

The third prominent finding concerning the teachers' perceptions of the model was its values in upgrading their understanding of important aspects in teaching cultural and intercultural contents. Among the 10 participants, Teachers B and D were the only two that appeared to hold a certain level of awareness of the four main components of ICC namely awareness, attitude, knowledge and skills. Yet, they acknowledged that their understanding was somehow at a superficial level. Being introduced to the model, they all seemed to be delighted by their better understanding of these objectives. Teacher B, for instance, shared that:

To tell the truth, before participating in the seminars, the objectives in teaching cultural aspects are similar to teaching other language skills. But now, I hoped my students can be aware of their own culture, understand and accept the differences among diverse cultures to help them communicate more suitably. Besides understanding their own cultures and other countries', I hope that will affect the awareness and attitudes of students so that they will behave properly and become good citizens (Teacher B, block 49). 
DOI: $\underline{10.51386 / 25815946 / \mathrm{ijsms}-\mathrm{v} 4 \mathrm{i} 5 \mathrm{p} 103}$

Teachers D, F and G also shared a similar comment that "from the model, I learned that there should be a stronger focus on students' awareness and attitude as well as skills and knowledge in teaching culture with the ICLT model" (Teacher D, block 112). Teacher F further believed that if they taught students in the way the model promoted, "at the end of the lesson, students would be able to understand another culture, raise their awareness of cultural values, accept the cultural experience, form good attitude besides knowledge and skills (Teacher F, Block 176).

\section{Teachers' perceptions of benefits and difficulties when applying the ICLT model}

To investigate more in-depth perceptions held by the teachers concerning the ICLT model, group interviews were conducted with the three teachers who agreed to participate in the second phase of the study using the ICLT model for lesson planning and implementation in classroom context. All lessons delivered were observed to ensure the model had been strictly abided by and classroom data were used as evidence and prompts for discussion in the group interviews. The central focus in these interviews was placed upon the specific benefits and challenges the teachers experienced when applying the model in actual teaching.

The most prominent finding regarding the benefits of using the ICLT model in teaching cultural aspects in such a high school context was the user-friendly nature of the model. All three teacher participants felt pleasant with the steps that were used in their teaching culture with the ICLT model. In the interviews, these participating teachers emphasized that "the model featured much resemblance with the CLT approach that they used for their teaching everyday with the same stages input (pre), practice (while) and output (production)" (Teachers D, block 112). They also voiced that the steps and cultural tasks were "familiar and easy to be applied" (Teacher E, block 143). The teachers also observed that while the main tasks from the textbooks could be well retained in this lesson model, the step of "Notice" in the lesson seemed to have an important value in promoting students' ability "to remember cultural aspects longer by comparing and contrasting the similarities and differences of typical features of cultures, and then formed good attitudes, behaved properly in real- life situations" (Teacher D, block 114).

Another noticeable benefit of the ICLT model as perceived by the teachers was that it had a strong focus on students' ICC beside their language skills. Three participating EFL teachers recognized that with the ICLT model, the objectives specified at the beginning of the lesson were achieved after teaching the period of the ICLT model in their comments in the observation sheets. As noted down in the observation sheet by teacher B, "this model helps boost students' language skills and raise their intercultural awareness". By putting the model into practice, the three teachers perceived the existence of four components of ICC such as awareness, attitudes, knowledge and skills that served as a crucial framework for teachers to design cultural lessons and evaluate students' performance during their lessons. This finding reflects Teacher G's idea in the first interview, stating that "students performed the tasks for a particular purpose with their concentration aimed at acquiring cultural knowledge" (Teacher G, block 205). It also echoes Teacher F's belief that "students showed their awareness and positive attitude towards cultural aspects through their participation in cultural activities. Students can remember the cultural contents better" (Teacher F, block 176).

The third perception that should be noted in application of the ICLT model was that the model provided teachers with a means to promote and develop both IC and LC for students through tasks. As can be seen in the results of the second interviews and observation sheets that all three teachers agreed that "teaching culture with that model helps student develop both language and intercultural knowledge, be aware of global issues and explore further new language from intercultural tasks" (Teacher B's comments in the observation sheet). This idea has much resemblance with what the teachers shared in their first interviews. In particular, Teacher $G$ maintained that "ICLT model developed language skills through intercultural communicative tasks such as: watch a video and discuss, listen and take notes, role play, discussions, storytelling, reading (e.g., read the passage and answer the questions), writing (e.g., write a letter to friends from other cultures to discuss some global issues), prediction" (Teacher G, block 207). In this way, most participating teachers believed that students with ICC would be intercultural speakers who can handle well social relationships and become good global citizen in this era. 
DOI: $\underline{10.51386 / 25815946 / \mathrm{ijsms}-\mathrm{v} 4 \mathrm{i} 5 \mathrm{p} 103}$

The last positive perception that high school teachers held about the ICLT model was the motivation it brought to teachers and students in the school. Two participating teachers (Teachers A and B) who practised teaching with the ICLT model said that "the model motivated them to read much and invest more time and energy for selecting materials" (Teacher A, Block 30). They further explained that the model helped them widen their cultural knowledge and thicken their experiences. As indicated by observation evidence, all three teachers agreed that, there was a higher level of interest in culture among students in topics related to ways of behaviours, cultural diversity, gender equality, and environment; therefore, students somehow paid attention to learning culture, the importance of culture in their lives. This observation seems to resonate Teacher C's comment in the first interview that the teaching cultural aspects with the ICLT model could help "build students' love for learning culture, tolerance in cultural diversity, erase cultural bias, avoid misunderstanding in communication, and improve language skills" (Teacher C, block 85).

With regard to the challenges the teachers encountered in applying the ICLT model, the first prominent obstacle reported was time limitation. The results from observations sheets showed that all three teachers often did not have enough time to cover all steps in one period. In the comments of observation sheets, it was evident that there was not sufficient time for many students to present their products at the "output" part and for teachers to inter-mingle cultural elements into one period. In the interviews, a common concern shared among the teachers was that they were afraid that "there would be a lack of time to run all steps of the ICLT model in only one period (45 minutes) of the current curriculum" (Teacher G, block 209). The worry over this shortage of time was also felt by Teacher B, saying that:

This model is the combination of other methods. However, it helps students remember cultural knowledge longer. It motivated teachers to use videos, pictures, and further information. Therefore, it is complicated and time-consuming for teachers to apply that model. Besides that, it is hard to transfer all contents in one period (Teacher B, block 59).

Another important difficulty perceived by these teachers in their application of the ICLT model was teachers' feeling of a lack of cultural knowledge. As found in the teachers' responses in the interviews, all three participants confessed that they felt unconfident when students asked them further information about cultural contents, so they needed time and energy to prepare what unclear information in advance so that they could give fulfil students' cultural curiosity in their process of accessing and creating new languages with cultural contents. Again, this concern has its resonance with the teachers' remarks in their first interviews. Particularly, Teacher C admitted that he himself as a learner, was taught language skills, vocabulary and grammar structures from the very young age instead of being informed about cultural knowledge. Therefore, he thought that he did not feel confident with his own cultural knowledge, which in turn became a challenge for him in teaching if he needed to tap into this aspect too deeply.

The most concerning issue that teachers perceived when using the ICLT model was the heavy workload that it brought about to teachers. Teacher E, for instance, thought that "it took them much time and energy to prepare this lesson, design activities and select teaching aids appropriately while teachers were busy with much stuff besides teaching such as marking, paper work" (Teacher E, block 147). Similarly, all three teachers said that they needed "to search for information about the topics in the textbooks; find out teaching materials such as pictures, video clips, stories related to the cultural contents that we [they] were going to teach" (Teachers A, block 28). Because the period "Communication and Culture" was considered the main content to teach cultural contents in high school textbooks, these teachers felt it difficult to try to connect two separate parts "Communication" and Culture" smoothly, exploit the typical features of two different cultures in these two parts, particularly Vietnamese culture and another one. Therefore, not every teacher would feel pleasant with that way of teaching.

Last but not least, one important barrier that the teachers honestly shared was their own perceived lack of motivation in teaching and learning cultural contents. As they shared in the first interviews, although they had favourable conditions for innovative teaching ideas. In reality, preparing students for the national exit exam with good results still dominated as the ultimate goal in teaching in learning. As such, even though they perceived a strong need to include cultural contents in teaching and develop their students' ICC, these content components 
DOI: $\underline{10.51386 / 25815946 / \mathrm{ijsms}-\mathrm{v} 4 \mathrm{i} 5 \mathrm{p} 103}$

were still treated as of secondary importance. Teacher F, for instance, said that he was afraid that "students are under pressure of testing, so they do not care much about cultural contents. The objectives of their teaching of the beginning of the school year are not related to improving students' ICC" (Teacher F, block 178). As a result, teachers' primary focus was still placed upon improving students' language skills.

\section{DISCUSSION}

The first major goal of this present study was to explore the teachers' reported current practice in teaching cultural contents and developing ICC for their students. As presented in the findings section, evidence from the teachers' interviews, first of all, indicated a high level of consciousness among the teachers concerning the importance of integrating cultural contents and developing students' competence for communicative in multicultural settings. In conjunction with this awareness, the teachers were also able to provide clear justifications for this integration. Accordingly, the teachers strongly emphasized the need to equip learners with a good ability to communicate properly with other people from various cultures, develop their language skills such as speaking and writing skills, avoid cultural breakdowns, which all help them succeed in their future career. This common perception held by the teachers in this study appears to show a high level of resonance with the beliefs held by teachers in studies conducted by Liaw (2006), Planken et al. (2004), and Popsecu and Iordachescu (2015). Teachers in these studies were also found to hold a strong belief that intercultural competence could improve learners' English communicative competence, especially speaking skills. In this sense, like participants in other studies, the teachers in the present study appeared to advocate the inclusion of cultural contents and aspects of intercultural competence in language teaching as this has positive effects on learners' ability to communicate in a foreign language.

Another important finding related to the teachers' current practice was their strong perception towards the favourable conditions for integrating cultural contents in their language classrooms. This finding seems to run contrast to those reported from previous studies in Vietnamese context in general concerning the negative impact that contextual factors (Canh, 2011, Canh\& Barnard, 2009; Hoang, 2010; Tomlinson \&Dat, 2004) exert on the teachers' freedom and possibility to carry out innovative ideas in teaching or simply to apply the communicative language teaching approach properly. On the contrary to those previous findings, the teachers in the current study consistently reported on the ideal conditions of facilities, learners' levels and motivation, the availability of native teachers at the school as well as great support from the administrative team to uphold their efforts in bringing in innovations in teaching practice. As such, the teachers believed that they all had the most favourable conditions for combining language and culture in their current practice.

Given the teachers' good awareness of the importance of developing learners' ICC in language teaching, their attention to this particular content was reported to be limited for a number of reasons. On the one hand, the teachers' objectives in including cultural contents in their lessons were found to be restricted only to the knowledge component, which was mainly framed and dictated by the textbooks and the prescribed curriculum. On the other hand, in teaching practice, the teachers still perceived a strong urge to primarily focus on language competence to prepare for students to pass the national high school exit exam. As such, cultural contents were minimally addressed, mainly through the period allocated for the "Communication and Culture" Section in the prescribed textbook. To a great extent, these findings echo what Hanna (2016), Gonen and Saglam (2012) and Gonen and Saglam (2012) reported earlier concerning the fact that teachers in various parts of the world still ignore the importance of teaching culture as a part of language teaching. Similar restrictions perceived by teachers that restrict their freedom and hinder teaching performance and learning outcomes have been commonly reported by previous studies in Vietnamese context (Canh, 2011, Canh\& Barnard, 2009; Hoang, 2010; Nguyen, 2018, Stefan, 2017). In many contexts, teachers' priority on language knowledge and skills over the cultural aspects as main teaching content due to has also been discussed extensively in several previous studies (e.g., Genc\&Bada (2005), Doganay and Yergaliyeva (2013), Planken et al. (2004). In this sense, the teachers' self-perceived tension between the need to cover cultural contents and focus more on students' ICC and the urge to prioritize language components to prepare students for a more structure-based examination seems to be the key aspect that needs to be addressed if a change in the teachers' practice is desired. To tackle the issue, however, a joint effort that both improves the teachers' understanding of the objectives and approaches in developing students' ICC and guarantees them of an official indication for a stronger focus on culture and ICC explicitly stated in the prescribed curriculum might be needed. 
DOI: $\underline{10.51386 / 25815946 / \mathrm{ijsms}-\mathrm{v} 4 \mathrm{i} 5 \mathrm{p} 103}$

Concerning the second research question that was aimed to investigate the teachers' initial perceptions of the ICLT model, the most notable finding revealed from the interviews was related to the teachers' strong belief in the feasibility of the model to be applied in their own context. Such a confidence in the ease to apply the model, first of all, was found to be rooted from the teachers' sensing of the model as teacher-friendly with clear step-by-step procedure. Furthermore, the underlying theoretical foundation that underpins each of the step in the model was also clearly provided. As explained in the interviews, the teachers also perceived that the ICLT model shared much similarity with features of the CLT method that they claimed to have employed in their teaching context. Even though the Notice step was perceived as a new feature for some teachers, the three-stage lesson model of input provision, practice and output production was seen as quite conventional from their perspective. Given this perception of similarity, the teachers showed much appreciation to the inclusion of the Notice step, drawing on Schmidt's Noticing Hypothesis (Schmidt, 1995, 2001) in which they believed would help raise learners' language and intercultural awareness and adjust their intercultural attitudes by exposing learners to more authentic learning tasks or activities so that they can attend, notice and make comparisons between unknown features of the input with familiar ones.

Another important finding related to the teachers' initial perceptions of the ICLT model was its values in refining their understanding of the key objectives in teaching cultural aspects and developing students' ICC. As earlier mentioned, although the teachers had full awareness of the importance of integrating cultural contents and promoting learners' ICC, their understanding of what aspects of culture and ICC should be addressed in teaching was found to single-faceted with a sole focus on cultural knowledge. As such, the teachers seemed to rely mainly on the provided content in the textbooks and strictly followed its readily designed structures. As a result of the seminars, however, the teachers reported to have gained a more thorough understanding of the components of intercultural communicative competence as suggested by Byram (1997). Accordingly, as the teachers stated in the interviews after the seminars, the four key components of attitudes, knowledge, skills and awareness have been updated as specific important objectives that they needed to pay more attention to. Such an extension in the teachers' repertoire might have an impact on their beliefs, confidence, which in turn might result in innovations in teaching practice (Borg, 2006), especially when the teachers were also equipped with a clear idea about how each of these objectives could be realized in classroom practice. In this sense, the teacher participants seemed to perceive that the newly-introduced model has helped refine and extend their understanding of the key objectives when integrating cultural aspects with language in teaching.

With such an updated perspective, these teachers further contended that the model could also help them improve the connection between the content included in the communication (Vietnamese culture) and Culture (other cultures) in the textbooks, so as to minimize the problem of isolating or separating content in this section as in their current teaching. Those findings reaffirm the results found in the action research by Tran and Duong (2018) in which the ICLT was proved to have a positive effect on EFL learners' linguistics competence and intercultural competence through learners' perceptions and their performance. In other words, evidence appears to hint that those findings in teachers' perceptions are parallel with the positive effects of the ICLT model on developing learners' language proficiency and cultural acquisition.

Such a positive effect brought about from the seminars delivered as part of the research project could be seen as a fruitful channel for imparting updated ideas to classroom practitioners. In reality in Vietnamese context, participating in professional development activities for high school teachers was found to be still limited (Nguyen, 2020), the exploitation of research projects and researchers as insiders of the researched context could provide a convenient and effective channel for enhancing professional activities for the teachers. As voiced by the teachers in this study, they themselves perceived a higher level of motivation to improve their own intercultural knowledge and competence participating in the project. It should be noted also that the positive impact reported in this study might partly be resulted from the fact that the seminars were delivered by an insider of the context and as part of research itself, the teachers were walked through the whole process of familiarising themselves with the model, developing lesson plans together, implementing their lessons in their own context plus having an opportunity to reflect upon the plus and minus of their own lessons. Such a design might be beneficial especially because these new ideas were not simply introduced to the teachers as in cases of one-shot conferences or workshops. Instead, the second phase in this study which allowed the teachers to gain hands-on experience in implementing the model could be seen as of crucial importance in convincing the teachers to actually employ the model in teaching in the future. 
DOI: $\underline{10.51386 / 25815946 / \mathrm{ijsms}-\mathrm{v} 4 \mathrm{i} 5 \mathrm{p} 103}$

With respect to the benefits and challenges the teachers experienced when putting the model into practice, the teachers' perceptions of the teacher-friendly nature of the model was reaffirmed. The most prominent benefit that was repeatedly mentioned by the teachers, however, was their belief that the model provided them with a platform for promoting a strong focus on students' ICC beside their language skills. As they further contended, although vocabulary and structures still functioned as the main teaching content that they scaffolded in these lessons to provide students with language functions to produce their intercultural communicative products, the model basically allowed them to integrate components of ICC into any kinds of language skills lesson that the textbooks provide. In this way, most participating teachers believed that students with ICC would become intercultural speakers who could be fluent in a foreign language and function appropriately and effectively, avoid misunderstanding and become good global citizen in the context of globalization. Students, as such, could perform the learning tasks for a particular purpose with their concentration directed and aimed at acquiring cultural contents. The teachers also perceived that those components of intercultural knowledge, attitudes, awareness, and skills could be used as a crucial framework to evaluate students' development of language competence as well as intercultural competence. Such a perception, to a great extent, signals the possibility that the teacher participants might make efforts in using the model in their teaching in the future if their purposes in teaching are to address both linguistic and intercultural communication ability for their students.

Another important plus of the model as perceived by the teachers was related to the motivation that it might bring to both learners and teachers in the school for further learning. As observed by the teachers, students appeared to show a higher extent of interest in exploring more about cultures when learning lessons designed in accordance with the model and with a clearer focus on cultural contents. As for teachers, there was also a confession that teaching cultural contents with the ICLT model created more motivation for teachers themselves to learn and explore more about diverse cultures around the world to deepen their own cultural knowledge as well as boost their students' intercultural communicative competence. These findings display a high level of resonance with the results reported by Tran and Duong (2018) in whichlearners were found to hold positive perceptions of ICLT, so they were motivated to learn the intercultural content through learning the language content and were aware that ICC functioned as an integral part of the necessary professional skills required for future jobs as well as their improvement in linguistic competence.

Turning to key challenges in the application of the model, time limitation compounded by heavy workload were reported as first barriers. On the one hand, the teachers all expressed a concern over the tight schedule with rigid curricular content, which might not allow them to try out all the ideal activities for languageculture integration teaching. The issue of teachers' concern over time restriction has been repeatedly reported by research into English teaching in Vietnamese context (e.g.,Canh, 2007; Canh\& Barnard, 2009; Hao, 2017, Nguyen, 2018). On the other hand, they all showed a certain level of worry over the fact that alignment with the model in lesson planning could result in a huge amount of preparation. Selecting materials and finding appropriate activities, searching for cultural information, video clips and stories took teachers much time and energy to prepare this lesson while teachers were busy with much stuff. Therefore, it comes as no surprise that teachers felt reluctant to fully adopt the ICLT model to their language teaching although they held positive attitudes toward the model. This finding highly supports the result that was found in Gu's (2016) study in which the huge amount of work was identified one of the key problem that deterred teachers from applying a new method.

Another key problem that was reported by the teachers in their application of the ICLT model was their perceived lack of cultural knowledge. As found in the teachers' responses in the interviews, insufficient cultural knowledge was reported as one of the barriers that made them reluctant to apply the ICLT model in their real teaching because ICC was seen as the field of knowledge that they had not learned at university. The issue of teachers' insufficient confidence with their own subject matter content knowledge or skills has been reported as one of the most prominent and long-lasting problem in different contexts. Arguments have also been made that attempts to improve teachers' teaching effectiveness needed to start from addressing the aspect of teachers' confidence. This further suggests that in the particular context of Vietnam where currently extensive efforts have been made across the country to empower teachers and improve their teaching quality, part of the vision should be drawn to the improvement of the aspect of teachers' cultural and intercultural knowledge apart from targeting their language proficiency and teaching methods and skills. 
DOI: $\underline{10.51386 / 25815946 / i j s m s-v 4 i 5 p 103}$

\section{IMPLICATION AND CONCLUSION}

This section discusses the practical implications of this study for the management levels from the Ministry of Education and Training to leaders of the English Department, institution managers, and EFL highschool teachers.

First, if high school teachers have an interest in application of the ICLT model in their teaching ICC, they should learn how to arrange time and organize proper activities so that they can handle their time budget and the objectives for each period.

Second, teachers themselves need to change their attitude in teaching languages and invest more time and energy on improving their cultural knowledge and their ways of teaching cultural aspects. They can search for cultural information on the Internet, in the paper documents. They should pay more attention to culture and ICC in their teaching English. The objectives should be clearly set out and culture should be mentioned in the objectives of the course at the beginning.

In addition, to create more motivation for students in learning culture, high school teachers can implement and adapt tasks appropriately according to their teaching environment, their students' levels. In addition, language teachers who would like to enhance ICC in their class can create interesting tasks which promote both linguistic competence and intercultural competence such as role-plays, presentation, telling stories, prediction, cultural Island, compare and contrast techniques (Eva Reid, 2015) to attract students and build their love for learning culture.

Moreover, the Ministry of Education and Training should organize more training activities, seminars to widen their knowledge of ICC, its components and objectives in teaching ICC; raise teachers' awareness of the importance of inclusion of culture in language teaching, enrich their teaching experiences, reduce the pressure of testing and paperwork; enhance teachers' knowledge of various ways of teaching with a view to improving the quality of teaching and learning. The curriculum can be changed if possible to provide teachers with more time for teaching the period "Communication and Culture".

Finally, institution managers should create more opportunities for teachers to access to teaching materials, videos clips, books, online resources related to teaching language with cultural contents. They should arrange time schedule properly so that high school teachers can feel comfortable to apply new teaching method, particularly using the ICLT in teaching cultural contents in the textbooks.

In conclusion, the current study, by introducing the ICLT model to teachers and accompanying them in putting the mode into use, has exemplified itself as a promising avenue for building a better connection between theory and classroom practice in language teaching. Evidence from the study findings showed certain values of this attempt in directly updating the teachers' current knowledge, awareness and confidence as well as laying foundations for more long-lasting development in the teacher community. Although a certain number of challenges in relation to both external contextual conditions and teachers' internal problems of insufficient confidence in their cultural and ICC knowledge and skills, the teachers were found to be fully aware of the need to pay closer attention to the cultural aspects in their language classroom. The ICLT model was wholeheartedly welcomed by the teachers who perceived it as user-friendly with a high extent of feasibility and similarity with the CLT approach they have been familiar with in their teaching context. To a great extent, the model could serve as an applicable platform that the teachers could employ to showcase a more balanced approach in making use of the textbook contents prescribed to them in the curriculum. However, it should be noted that these initial positive perceptions and experimental implementation of the model in teaching practice might not guarantee a long-term commitment from the teachers unless continuing efforts for teacher training, teaching practice and reflection are stably in place. In other words, what the current study has offered could be seen as a departure for more sustainable future endeavours in promoting the use of this model among the teacher community, for which a clearer highlight on the importance of cultural contents and ICC needs to be officially featured in the curriculum, and teachers need to be provided with further training opportunities to upgrade their own cultural and intercultural expertise as well as practical teaching skills that well uphold a more language-culture balanced teaching approach. 


\section{ABOUT THE AUTHORS}

Nguyen Thi Ngoc Hanhis a teacher of English at Thu KhoaNghia High School, Vietnam. She completed abachelor's degree of English in Education in 2007. She is currently an MA student at Can Tho University. Herresearch interests includeteaching methodology and students'intercultural communicative competence. Nguyen HaiQuan is currently a Professor at the School of Foreign Languages, Can ThoUniversity, Vietnam. He carries studies on language teaching approaches and Intercultural Communicative Competence. He published articles in different journals.

\section{REFERENCES}

[1] Atay, D. Kurt, G. Çamlıbel, Z. Ersin, P. Kaslığlu, Ö. (2009). The role of intercultural competence in foreign language teaching.İnönüÜniversitesiEğitimFakültesiDergisi.Cilt 10.Sayı 3.123-135 ss.

[2] Bachman and Palmer's (1996). Language Testing in practice: Designing and Developing Useful Language Tests. Oxford University Press.

[3] Barletta Manjarrés, N. (2009). Intercultural competence: Another challenge. Profile, 11, 143-158.

[4] Byram, M. (1989). Cultural Studies in Foreign Language Education.Clevedon : Multilingual Matters.

[5] Byram, M. (1997).Teaching and assessing intercultural communicative competence. Philadelphia, PA: Multilingual Matters.

[6] Byram, M., Gribkova, B., \& Starkey, H. (2002). Developing the intercultural dimension in language teaching: A practical introduction for teachers. Strasbourg: Council of Europe. Communication, 2, 27-54.

[7] Boontharika (2018). Teachers' perceptions towards promoting intercultural communicative competence in the EFL classroom.rEFLections, 25(2)

[8] Borg (2006).Teacher cognition and language education: Research and practice. London: Continuum.

[9] Canh, L. V. (2007). Teachers' beliefs about curricular innovation in Vietnam: A preliminary study. In Y. H. Choi \& B. Spolsky (Eds.), ELT curriculum innovation and implementation in Asia (pp. 191- 216). Seoul, Korea: Asia TEFL.

[10] Canh, L. V. (2011). Form-focused instruction: A case study of Vietnamese teachers' beliefs and practices. (Unpublished doctoral dissertation), University of Waikato, Hamilton, New Zealand.

[11] Canh, L. V., \& Barnard, R. (2009). Curricular innovation behind closed classroom doors: A Vietnamese case study. Innovating EFL Teaching in Asia, 24(2), 20-33.

[12] Canale, M., \& Swain, M. (1980). Theoretical bases of communicative approaches to second language teaching and testing. Applied Linguistics, 1, 1-47.

[13] Cheng, C. (2007). The Influence of EFL teachers" understanding of intercultural competence on their self-reported pedagogical practices in higher education institutes of technology in Taiwan (Doctoral dissertation). Retrieved from ProQuest Dissertations and Theses database. (UMI No. 3249489)

[14] Chomsky, N. (1965). Aspects of the Theory of Syntax.Cambridge, Massachusetts: The M.I.T. Press.

[15] Council of Europe (2001). Common European Framework of Reference for Languages: Learning, Teaching and Assessment. Strasbourg.

[16] Cullen, B. (2000). Practical Techniques for Teaching Culture in the EFL Classroom. In: The Internet TESL Journal. Vol. 6, No. 12. (2000).[online]. [cit. 20.8. 2014]. Available on the internet: http://iteslj.org/Techniques/Cullen-Culture.html.

[17] Crystal, D. (2003). English as a global language (2nd, 1st ed. in 1997 ed.). Cambridge: Cambridge University Press.

[18] Doganay, Y., \&Yergaliyeva, A. M. (2013). The impact of cultural based activities in foreign language teaching at intermediate (B1) level. Procedia-Social and Behavioral Sciences, 89, 734-740.

[19] Furstenberg, G. (2010). Making culture the core of the language class: Can it be done? The Modern Language Journal, 94(2), 329332. 


\section{DOI: $\underline{10.51386 / 25815946 / \mathrm{ijsms}-\mathrm{v} 4 \mathrm{i} 5 \mathrm{p} 103}$}

[20] [20] Garretts-Rucks, P. (2010). The Emergence of U.S. French Language Learners' Intercultural Competence in Online Classroom Discussions.In Doctoral dissertation. USA: University of Wisconsin-Madison.

[21] Garrido, C., \& Alvarez, I. (2006). Language teacher education for intercultural understanding. European Journal of Teacher Education, 29(2), 163-179.

[22] Genc, B., \&Bada, E. (2005). Culture in language learning and teaching.The Reading Matrix, 5(1), 73-84.

[23] Gonen, S. I. K., \&Saglam, S. (2012). Teaching culture in the FL classroom: Teachers' perspectives. IJGE: International Journal of Global Education, 1(3), 26-46.

[24] Gu, X. (2016). Assessment of intercultural communicative competence in FL education: A survey on EFL teachers` perception and practice in China. Language and Intercultural Communication, 16(2), 254-273.

[25] Hao, D. T. T. (2017). Identify factors that negatively influence: Non-English major students' speaking skills. Higher Education Research, 2(2), 35-43.

[26] Hong, S. (2008). The role of heritage students in incorporating culture into language teaching .South Asia Language Pedagogy and Technology, 1.Retrieved from https://apps.cla.umn.edu/directory/items/publication/316719.pdf.

[27] Huhn, P. (1978). LandeskundeimLehrbuch: Aspekte der Analyse, Kritik und korrektivenBehnadlung. In: Byram, M. 1989. Cultural Studies in Foreign Language Education.Multilingual Matters.

[28] Hymes, D. (1972). “On communicative competence”, en J. Pride y J. Homes (eds.), Sociolinguistics. Harmondsworth: Penguin.

[29] Kachru, B. (1985). Standards, codification and sociolinguistic realism: English language in the outer circle. In R. Quirk and H. Widowson (Eds.), English in the world: Teaching and learning the language and literatures (p. 11-36). Cambridge: Cambridge University Press.

[30] Karabinar, S., \&Guler, C. Y. (2013). A review of intercultural competence from language teachers“ perspective. Procedia-Social and Behavioral Sciences, 70, 1316-1328.

[31] Krashen, S. (1985). The input hypothesis. New York: Longman.

[32] Kirkpatrick, A. (2007). World Englishes: Implications for international communication and English language teaching. Cambridge: Cambridge University Press.

[33] Kramsch, C. (1993).Context and culture in language teaching. Oxford: Oxford University Press.

[34] Kramsch, C. (1998). Language and Culture.Oxford : Oxford University Press.

[35] Liaw, M. L. (2006). E-learning and the development of intercultural competence.Language Learning \& Technology, 10(3), 49-64.

[36] Long, M. H. (1996). The role of the linguistic environment in second language acquisition.In W. C. Ritchie \& T. K. Bhatia (Eds.), Handbook of second language acquisition (pp. 413-468). New York: Academic Press.

[37] McKay, S., \&Bokhorst-Heng, W. D. (2008). International English in its sociolinguistic contexts: Towards a socially sensitive EIL pedagogy. New York: Routledge.

[38] MOET. (2006). Chuongtrinhgiaoduc pho thong (A general education curriculum). Hanoi: Nhaxuat ban giaoduc (Education Publishing House).

[39] Moeller, A. K. \& Nugent, K. (2014). Building intercultural competence in the language classroom.Faculty Publications: Department of Teaching, Learning and Teacher Education. 161.

[40] Nguyen, H. Q. (2018). Speaking pedagogy: Insights from Vietnamese EFL teachers' cognitions and classroom practice.(Unpublished doctoral dissertation), University of Wollongong.

[41] Nguyen, D. B. (2020). Vietnamese High School Teachers' Perceptions of the Impact of the Existing PD Activities and Their Needs for Further Development.(Unpublished Master thesis), Can Tho University.

[42] Planken, B., van Hooft, A., \&Korzilius, H. (2004). Promoting Intercultural Communicative Competence through Foreign Language Courses.Business Communication Quarterly, 67(3), 308-315. 


\section{DOI: $\underline{10.51386 / 25815946 / \mathrm{ijsms}-\mathrm{v} 4 \mathrm{i} 5 \mathrm{p} 103}$}

[43] Popescu, T., \&Iordachescu, G. D. (2015). Raising Students' Intercultural Competence through the Process of Language Learning.Procedia-Social and Behavioral Sciences, 197, 2315-2319.

[44] Reid, E. 2014. Intercultural Aspects in Teaching English at Primary Schools. Frankfurt am Main: Peter Lang.

[45] Schmidt, R. (1995). Consciousness and foreign language learning: A tutorial on the role of attention and awareness in learning. In R. Schmidt (Ed.), Attention and awareness in foreign language learning (pp. 1-63). Honolulu, HI: University of Hawaii, Second Language Teaching \& Curriculum Center.

[46] Schmidt, R. (2001). Attention. In P. Robinson (Ed.), Cognition and second language instruction (pp. 3-32). Cambridge: Cambridge University Press.

[47] Sercu, L. (2005). Teaching foreign languages in an intercultural world. In M. Byram\& A. Phipps (Eds.), Foreign language teachers and intercultural competence (pp. 1-18). Buffalo: Multilingual Matters, Ltd.

[48] Sinicrope, C., Norris, J., \& Watanabe, Y. (2007). Understanding and assessing intercultural competence: A summary of theory, research, and practice (technical report for the foreign language program evaluation project). Second Language Studies, 26(1), 1-58.

[49] [49] Tomlinson, B., \&Dat, B. (2004). The contributions of Vietnamese learners of English to ELT methodology.Language Teaching Research, 8(2), 199-222.

[50] Tran, T. Q. \&Seepho, S. (2016). An Intercultural Communicative Language Teaching Model for EFL learners. Research Gate. Retrieved https://www.researchgate.net/publication/304086067_An_Intercultural_Communicative_Language_Teaching_Model_for_EFL_Lea rners

[51] Tran, T. Q. (2016). An Intercultural Communicative Language Teaching for EFL Learners.(Doctoral dissertation).NakhonRatchasima: Suranaree University of Technology.

[52] Tran, T. Q. \& Duong, T. M. (2018).The effectiveness of the Intercultural Communicative Language Teaching for EFL learners.Asian-Pacific Journal of Second and Foreign Language Education: 3:6. Retrieved from https://doi.org/10.1186/s40862-0180048-0

[53] Young, T. J., \&Sachdev, I. (2011). Intercultural communicative competence: Exploring English language teachers` beliefs and practices. Language Awareness, 20(2), 81-98. 